\title{
Educação e serviços de saúde: avaliando a capacitação dos profissionais
}

\author{
Education and health services: \\ evaluating professional training
}

\footnotetext{
${ }^{1}$ Departamento de Medicina Preventiva e Social, Faculdade de Ciências Médicas, Universidade Estadual de Campinas. Cidade Universitária Prof. Zeferino Vaz, Campinas, $S P$ 13083-970, Brasil. slabbate@head.fcm.unicamp.br
}

\begin{abstract}
This paper analyzes the results of a follow-up study and evaluation of the Specialization Course in Public Health administered from 1993 to 1995 by the Department of Preventive and Social Medicine at the School of Medical Sciences, Universidade de Campinas, Brazil. The study was conducted during the course and with a follow-up several months later. Students reported on their professional activities, difficulties and facilities in performing them, and their commitment to the public health services in which they worked. They also expounded on their needs and expectations regarding specialized training in public health. At the end of the required course load (first semester) and the optional courses (second semester), students evaluated the course content's relevance, their own understanding, and the strengths and weaknesses of the respective teaching strategies. Finally, six and eight months after the courses, the professionals evaluated how they were able to apply their new knowledge to their work. Various research instruments were used, including group dynamics, individual questionnaires, and focal groups, comprising a broad methodological approach. A single sample of individuals was thus studied at different moments with regard to this experience.
\end{abstract}

Key words Health Education; Graduate Education; Continuing Education; Health Services

Resumo Análisa-se os resultados de pesquisa de acompanhamento e avaliação do Curso de Especialização em Saúde Pública realizado pelo Departamento de Medicina Preventiva e Social da Faculdade de Ciências Médicas da UNICAMP, turmas de 1993 e 1995. A investigação foi realizada durante o curso e alguns meses depois do término do mesmo. Os alunos informaram suas atividades profissionais, as dificuldades e facilidades em desenvolvê-las e o compromisso com os serviços públicos de saúde nos quais trabalhavam; informaram também sobre suas expectativas em relação à especialização em saúde pública. Ao final das disciplinas, os alunos avaliaram a relevância dos conteúdos transmitidos, sua compreensão em relação aos mesmos e os erros e acertos das estratégias didáticas utilizadas. Transcorridos seis e oito meses do final do curso, os profissionais avaliaram a aplicação do que haviam aprendido. Instrumentos de levantamento de dados, tais como, dinâmicas de grupo, questionários individuais e grupos focais, compuseram uma abordagem metodológica, mediante a qual uma mesma clientela foi investigada a respeito de uma experiência que estava sendo vivenciada.

Palavras-chave Educação em Saúde; Educação de Pós-graduação; Educação Contínua; Serviços de Saúde 


\section{Introdução}

“Recurso humano é gente, gente que trabalha para viver; que tem seus próprios objetivos; que se comunica para superar problemas; recurso humano é gente, gente que anseia por proporcionar e desfrutar de uma melhor qualidade de vida!" (Divulgação em Saúde para Debate, no 14, 1996:04.)

O avanço da organização dos serviços de saúde no Brasil na perspectiva da construção do SUS - Sistema Único de Saúde - traz novos desafios para a capacitação dos profissionais de saúde pública que atuam nos diversos serviços de saúde. O ‘novo sanitarista’ precisa tanto dispor de conceitos da Epidemiologia e das Ciências Sociais, para compreender as formas de as pessoas adoecerem e os determinantes político-institucionais da organização do sistema de saúde brasileiro, como adquirir domínio técnico nas suas diversas áreas de atuação: do planejamento ao sistema de informações, do entendimento dos problemas ambientais à atuação didático-pedagógica, da saúde do trabalhador ao domínio de um instrumental estatístico básico, dos paradigmas organizacionais adequados às novas realidades regionais à organização e gestão dos serviços de autocusto e complexidade tecnológica. Deve também assumir uma postura ética que signifique incorporar e compartilhar um conjunto de valores que levem em conta os ideais de bem comum e de justiça, bem como a necessidade de praticar ações úteis produtivas nas quais profissional e cliente possam considerar-se sujeitos e cidadãos.

No sentido de contribuir concretamente para a formação desse tipo de recursos humanos, o Departamento de Medicina Preventiva e Social (DMPS/FCM/UNICAMP) da Faculdade de Ciências Médicas da Universidade Estadual de Campinas vem oferecendo, desde 1982, o Curso de Especialização em Saúde Pública para profissionais de nível universitário já inseridos nos serviços de saúde ou interessados em buscar a capacitação necessária para vir a atuar.

Trata-se de uma experiência que, embora bem consolidada em Campinas e região, não havia sido motivo de um processo sistemático de avaliação que permitisse obter informações sobre o seu impacto no aperfeiçoamento profissional dos alunos e, como decorrência, a possível influência nos serviços de saúde.

Dessa forma, pensou-se na realização de uma investigação que pudesse aproximar-se basicamente do seguinte questionamento: uma vez que muitos profissionais têm feito cursos de saúde pública para tornarem-se sanitaris- tas, qual o significado dessa experiência para esses profissionais, considerando-se sua inserção institucional e as várias atividades pelas quais são responsáveis? Assim, a pesquisa então proposta teve como objetivo geral identificar a influência do curso na prática profissional dos alunos e, como objetivos específicos: caracterizar o perfil do profissional de saúde que freqüenta o curso; compreender a maneira pela qual os profissionais/alunos relacionavam os diversos conteúdos e habilidades transmitidos à sua prática, e ainda de que forma o curso tem instrumentalizado os alunos para aperfeiçoar a competência profissional, considerando os níveis técnico, político-crítico e ético. Finalmente, interessava saber se os profissionais conseguiam implantar no cotidiano dos serviços alguns dos projetos pensados durante o curso.

Informa-se que o detalhamento do processo da investigação e dos resultados encontramse nos relatórios enviados ao Conselho Nacional de Desenvolvimento Científico e Tecnológico - CNPq, de 1994 a 1997, consolidados em dois relatórios técnicos, respectivamente, L'Abbate et al., 1997a; L'Abbate et al., 1997b, bases para a elaboração deste artigo.

\section{A relevância da capacitação dos recursos humanos na área da saúde pública}

Parte-se do pressuposto de que trabalhadores de saúde não devem ser considerados propriamente insumos ou recursos, mas sujeitos, com potencialidade de desenvolver-se constantemente em busca da autonomia possível, capazes de aderir a projetos de transformação (Campos, 1994; Mattos, 1996; L’Abbate, 1997c), sem deixar de reconhecer que mudanças substanciais politicamente viáveis tendem a se realizar pela ação conjunta de indivíduos articulados com movimentos sociais de sustentação, de acordo com Paim \& Nunes (1992:263).

No caso dos profissionais que atuam na rede básica de saúde, é importante resgatar o estudo de Gonçalves (1994), caracterizando o processo de trabalho do médico sanitarista e dos demais profissionais que compõem a equipe de saúde em centros de saúde, revelando a peculiaridade da utilização da tecnologia, como saber e como prática, quando se trata do campo da saúde pública. Em outro texto, o mesmo autor manifesta preocupação em apontar caminhos mais inovadores para a formação e capacitação dos profissionais de saúde, mesmo considerando que os profissionais assumem, no geral, processos de trabalho específi- 
cos, em grande parte já determinados, e estão inseridos em instituições de saúde, com objetivos também determinados (Gonçalves, 1992).

Ao propor um projeto de educação continuada como uma possibilidade promissora, quando se considera a formação dos recursos humanos para a área da saúde coletiva, Paim (1993:9) afirma que "tendo em conta a natureza coletiva do objeto e a diversidade dos meios de trabalho pode-se afirmar, resumidamente, que o agente das práticas de saúde coletiva tende a ser simultaneamente um 'técnico de necessidades sociais de saúde' e um 'gerente de produção de serviços'. No geral, este profissional está em vinculação com o Estado, tendo suas “atividades básicas (voltadas) para: vigilância e controle das necessidades sociais de saúde; planificação, gestão, controle e avaliação de práticas de saúde; elaboração e difusão de concepções sobre saúde (consciência sanitária)" (os grifos são do autor). Para Schraiber (1991:2), o desempenho do trabalhador é um problema do "domínio em um saber-fazer dos problemas do trabalho", produzidos " na dinâmica de realização deste como intervenção técnica adequada às demandas sociais".

L'Abbate (1997c:275), baseada em Rios (1993), observa que esse saber fazer deve ser um saber fazer bem, no sentido de um saber que leve em conta o técnico, o político e o ético. Para o profissional de saúde, não basta saber, é preciso “articular responsabilidade, liberdade e compromisso".

Discutindo os novos paradigmas hegemônicos na forma de atendimento à saúde (uso maciço de tecnologia, concentração de profissionais, sobretudo médicos, nos grandes centros, tribalização dos profissionais, de acordo com as diversas categorias), Machado (1995: 54), defende a idéia de que "trabalhadores de saúde são um bem público, uma utilidade pública". Ou seja, se o setor público emprega maciçamente trabalhadores (52\% do total de empregos no setor saúde), se "o trabalho em saúde não deixa ninguém impune, pois ele impõe, diferentemente de outros ramos da economia, um significativo envolvimento emocional $e$ ético com a pessoa que busca assistência médi$c a "$ - e, acrescento, assistência à saúde -, propor processos de capacitação cada vez mais eficientes e inovadores é também um dever das instituições formadoras públicas: as universidades em associação com os serviços.

$\mathrm{Na}$ mesma linha de raciocínio, Garrafa (1995:48) destaca a condição do concurso de profissionais íntegros como "pré-requisito indispensável para o bom desenvolvimento de qualquer programa sanitário, quando se consi- dera o processo da Reforma Sanitária/SUS no contexto do novo paradigma da ética da responsabilidade individual e pública, imprescindível nos dias atuais, frente a valores como justiça, cidadania e liberdade".

Dessa forma, qualquer projeto de capacitação de profissionais de saúde no campo da saúde pública deve levar em conta esse conjunto de premissas e deve visar ao desenvolvimento de uma competência que construa uma instrumentalização técnica e política, articulada com a ética. O desenvolvimento desta tripla dimensão tem sido exatamente o propósito pretendido com o Curso de Especialização em Saúde Pública, conforme se verá no próximo item.

\section{Características gerais do Curso de Especialização em Saúde Pública do Departamento de Medicina Preventiva e Social da Faculdade de Ciências Médicas da UNICAMP (DMPS/FCM/UNICAMP)}

Nos seus 15 anos de existência, o Curso de Especialização em Saúde Pública do DMPS/FCM/ UNICAMP passou por várias reformulações, conservando, contudo, os conteúdos básicos constitutivos da formação do sanitarista e perfazendo uma carga horária de 500 a 600 horas anuais.

Até 1989, o curso compunha-se das disciplinas clássicas para a formação do profissional de saúde pública, ministradas de forma seqüencial durante todo o ano, sem que houvesse uma distinção muito clara entre conteúdos introdutórios e específicos, a não ser no interior de cada uma. Todos os alunos cursavam todas as disciplinas.

Discussões e avaliações entre os docentes e alunos ao final de cada curso, bem como as constantes transformações da própria organização do sistema de saúde, levaram à necessidade de reestruturar a disposição das disciplinas, de modo que conteúdos básicos estivessem separados de conteúdos específicos, permitindo ao aluno se capacitar, tanto em relação aos fundamentos da saúde pública, como em relação à instrumentalização específica em algumas áreas.

A síntese desse processo de contínuas mudanças, aliado à necessidade de atribuir à Especialização o nível de pós-graduação latu sensu (UNICAMP, 1984-1993), resultou no formato do curso ministrado em 1993 e em 1995, composto de sete disciplinas obrigatórias, num total de 315 h/aula, e cinco disciplinas optativas com carga horária variando de 90 a 180 horas. 
As primeiras constituíam-se por Saúde e Sociedade, Pesquisa em Serviços de Saúde, Introdução à Epidemiologia, Bioestatística Aplicada à Saúde Pública, Introdução ao Planejamento e Administração em Saúde, Introdução à Saúde Ambiental e à Saúde Ocupacional, tendo sido as duas últimas substituídas no curso de 1995 por Práticas de Saúde Pública I e II, conservando-se parte dos conteúdos das antigas disciplinas e acrescentando-se a análise e discussão de experiências relacionadas a programas de saúde. Como disciplinas optativas foram ministradas: Planejamento e Administração em Serviços de Saúde, Epidemiologia Aplicada, Educação em Saúde, Saúde Ambiental e Saúde Ocupacional. Para obter o título de Especialista em Saúde Pública, o aluno deveria fazer todas as disciplinas obrigatórias e, pelo menos, uma disciplina optativa, não se vetando ao aluno cursar mais de uma, dependendo das possibilidades.

O corpo discente do Curso de Especialização em Saúde Pública tem sido composto de graduados de nível superior de todas as áreas de conhecimento, que estejam interessados em se especializar em saúde pública ou que já tenham atuação direta nos serviços públicos de saúde em seus vários níveis de abrangência (municipal, estadual e federal), bem como da área de saúde das universidades. Em comum acordo com as instituições que liberam os alunos, o curso é ministrado em cinco períodos ou dois dias e meio - semanais. Assim os profissionais mantêm suas atividades nos serviços onde atuam.

O corpo docente do curso é composto pela quase totalidade dos professores do Departamento de Medicina Preventiva e Social, de docentes de outras instituições acadêmicas e de serviços. Em certas atividades que exigem maior instrumentalização e monitoramento dos alunos, vêm participando profissionais dos Laboratórios do DMPS (Laboratórios de Epidemiologia/LAPE, de Planejamento e Administração/ LAPA, e de Comunicação e Educação em Saúde/LACES).

Não pertencendo ao elenco de cursos tradicionalmente oferecidos pela Faculdade de Ciências Médicas da UNICAMP, e resultando muito mais de uma preocupação do Departamento de Medicina Preventiva e Social em colaborar para a formação e aperfeiçoamento dos profissionais de saúde, tal empenho vem encontrando, ao longo desse tempo, respostas positivas das instituições de saúde, sobretudo as do setor público da região de Campinas que, ano a ano, enviam um grande número de profissionais para se submeterem ao processo de seleção do curso. A concretização do curso vem se dando mediante convênios firmados entre a UNICAMP e a Secretaria de Estado da Saúde/SES de São Paulo (Tabela 1).

Em relação ao contexto mais próximo, considerando os cursos analisados, o de março a dezembro de 1993 e o de agosto de 1995 a junho de 1996, ambos ocorreram durante o governo municipal do PSDB, cuja Secretaria da Saúde foi, durante todo o tempo, coordenada por uma médica, professora do Departamento de Medicina Social e Preventiva da Faculdade de Ciências Médicas da Pontifícia Universidade Católica de Campinas (PUCCAMP).

\section{Metodologia}

A investigação realizou-se segundo o modelo 'painel' que consiste “na coleta de dados de uma mesma amostra através do tempo” (Richardson et al., 1985:94). Para esses autores, a intenção é captar possíveis mudanças e, nesse sentido, aproximar-se dos estudos de tendências e coortes. No caso desta pesquisa, os indivíduos investigados consistiam na totalidade dos alunos matriculados nos cursos de Saúde Pública de 1993 e 1995. Mas, caso se deseje, eles podem ser considerados uma amostra dos 450 profissionais que fizeram o curso no DMPS, desde 1982. Além disso, as mudanças foram mais intuídas do que constatadas empiricamente, conforme se verá na discussão dos resultados. Apesar de tratar-se de uma população de fácil acesso, alunos de um curso, com os quais se tinha um contato semanal, todos os alunos não responderam a todos os questionários. Esta é uma das dificuldades das pesquisas de tipo painel, advertem os autores citados.

No período de ano e meio, a partir do início dos cursos, respectivamente março de 1993 e agosto de 1995, houve quatro momentos de abordagem aos alunos, contemplando diferentes instrumentos de coleta de informações, conforme Figura 1.

No geral, as variáveis pesquisadas eram de natureza qualitativa, e os questionários, elaborados em conjunto com a equipe de bolsistas, tiveram algumas de suas questões inspiradas no Autodiagnóstico Funcional, conforme MS/ FNS/CENEPI, 1993. Observaram-se também, na sua confecção, as recomendações de Goode \& Hatt (1972).

No quarto momento da pesquisa, além de questionário individual, recorreu-se também ao grupo focal, que, de acordo com Westphal et al. (1996:473), "é uma técnica de pesquisa que utiliza as sessões grupais como um dos foros fa- 
Tabela 1

Dados institucionais do Curso de Especialização em Saúde Pública DMPS/FCM/UNICAMP - 1985 a 1995.

\begin{tabular}{|c|c|c|c|c|c|c|c|}
\hline Ano & $\begin{array}{l}\text { Tipo de clientela } \\
\text { (corpo discente) }\end{array}$ & Convênio & $\begin{array}{l}\text { Seleção dos } \\
\text { candidatos }\end{array}$ & $\begin{array}{l}\text { Duração } \\
\text { (meses) }\end{array}$ & $\begin{array}{l}\text { Carga horária } \\
\text { total (horas) }\end{array}$ & Inscritos & Aprovados \\
\hline 1985 & $\begin{array}{l}\text { Profissionais de área biológica } \\
\text { ligados ao setor saúde com } \\
\text { vínculo institucional aos serviços } \\
\text { de saúde públicos estaduais } \\
\text { e municipais e universidades. }\end{array}$ & SES & $\begin{array}{l}\text { Prova escrita, } \\
\text { análise de currículo, } \\
\text { entrevista }\end{array}$ & 10 & 600 & 193 & 40 \\
\hline 1986 & $\begin{array}{l}\text { Profissionais de área biológica } \\
\text { e não biológica com vínculo } \\
\text { institucional aos serviços de saúde } \\
\text { públicos, estaduais e municipais } \\
\text { e universidades }\end{array}$ & SES & Idem 1985 & 10 & 600 & 115 & 39 \\
\hline 1987 & Idem 1986 & SES & $\begin{array}{l}\text { Prova escrita, } \\
\text { análise de currículo }\end{array}$ & 9 & 600 & 92 & 42 \\
\hline 1988 & Idem 1987 & SES & Idem 1987 & 7 & 500 & 69 & 39 \\
\hline 1989 & Idem 1988 & SES & $\begin{array}{l}\text { Prova escrita, } \\
\text { análise de currículo, } \\
\text { entrevista }\end{array}$ & 10 & 600 & 112 & 42 \\
\hline 1991 & Idem 1989 & SES & Idem 1989 & 10 & 536 & 88 & 35 \\
\hline 1993 & Idem 1991 & SES & Idem 1991 & 10 & 536 & 64 & 37 \\
\hline 1995 & Idem 1993 & SES & $\begin{array}{l}\text { Análise de currículo, } \\
\text { entrevista }\end{array}$ & 10 & 536 & 103 & 35 \\
\hline
\end{tabular}

Fonte: Arquivo do DMPS.

Em 1990, 1992 e 1994 o curso não foi ministrado.

Figura 1

Desenho de pesquisa de avaliação do Curso de Especialização em Saúde Pública DMPS/FCM/UNICAMP, 1993 e 1995.

Momentos da pesquisa.

\section{I- Início do curso}

II- Final do 1ㅇs semestre

\section{III- Final do 2o semestre}

IV-Seis meses após o término do curso

\begin{tabular}{|c|c|c|c|c|}
\hline Objeto & $\begin{array}{l}\text { Perfil da clientela } \\
\text { Dificuldades e facilidades } \\
\text { na prática profissional } \\
\text { Expectativa em relação } \\
\text { ao curso }\end{array}$ & $\begin{array}{l}\text { Compreensão dos } \\
\text { conteúdos } \\
\text { Críticas às disciplinas } \\
\text { obrigatórias } \\
\text { Conteúdo e didática }\end{array}$ & $\begin{array}{l}\text { Alcance dos objetivos } \\
\text { e expectativas } \\
\text { Relação das disciplinas } \\
\text { obrigatórias e optativas } \\
\text { Aplicabilidade dos conteúdos } \\
\text { das disciplinas optativas } \\
\text { Conteúdo e didática }\end{array}$ & $\begin{array}{l}\text { Volta do egresso ao trabalho: } \\
\text { repercussão institucional } \\
\text { Implementação de projetos }\end{array}$ \\
\hline Instrumentos & $\begin{array}{l}\text { Análise de currículo } \\
\text { Questionário } 01 \text { e } 02 \\
\text { Dinâmica de grupo }\end{array}$ & $\begin{array}{l}\text { Questionário } 03 \\
\text { Dinâmica de grupo }\end{array}$ & Questionário 04 & $\begin{array}{l}\text { Questionário } 05 \\
\text { Grupo focal }\end{array}$ \\
\hline
\end{tabular}


cilitadores da expressão de características psicossociológicas e culturais"; enfim, diz respeito “a uma sessão grupal em que os sujeitos do estudo discutem vários aspectos de um tópico específico".

Dentre as várias possibilidades de utilização do grupo focal, está a de avaliar uma experiência tomando-se como referência os sujeitos que dela compartilharam (Bertrand et al., 1992; Westphal, 1992). Nesse caso, os alunos, alguns meses após o término do curso, puderam, num reencontro de cerca de três horas, debater questões relacionadas ao curso e ao seu 'novo' papel profissional, tendo em vista os serviços de saúde onde atuavam.

Observaram-se os vários cuidados que a aplicação do grupo focal exige, conforme recomendam os autores citados acima: desde o planejamento até a preparação da reunião, seu registro em vídeo e em cassete, organização de todo o material e análise. Esse instrumento permitiu um tratamento mais dinâmico e participativo de temas já abordados nos questionários aplicados individualmente. Além disso, novos temas surgiram, contribuindo para ampliar os resultados da investigação (L'Abbate et al., 1997a, 1997b).

\section{Apresentação e discussão dos resultados}

Foram sujeitos da investigação todos os alunos das turmas de 1993 e de 1995 (respectivamente 37 e 35). O número de entrevistados variou no decorrer do painel, seja por se tratar de atividades das quais apenas uma parte participou (por exemplo, as disciplinas optativas), seja pela dificuldade intrínseca ao desenho da pesquisa, conforme assinalado. No entanto, dado o recorte que se procurou fazer, além de avaliar o impacto de um curso aproximar-se da maneira de ser e de pensar de um grupo de profissionais do campo da Saúde Pública, a análise não foi prejudicada. Neste item, analisam-se as informações consideradas mais relevantes dos dois grupos, com destaque para as de caráter qualitativo.

\section{Primeiro momento: caracterização da clientela, limites e possibilidades da prática profissional, necessidades e expectativas em relação ao curso}

Nos 15 anos de existência do Curso de Especialização em Saúde Pública, cerca de 450 profissionais já se capacitaram, dos quais 309 nos últimos dez anos. A Tabela 1 permite visualizar as principais características do curso no período de 1985 a 1995. Ao longo desse tempo, atendeu-se a uma clientela basicamente ligada ao setor público e, em grande maioria, do sexo feminino, acompanhando a tendência de feminização maciça da mão-de-obra empregada no setor saúde (Tabela 2).

Em relação à idade, mais da metade dos profissionais dos dois grupos encontravam-se na faixa de trinta a quarenta anos. Na turma de 1993 havia maior número de alunos com menos de trinta anos do que no grupo de 1995. O tempo de vínculo com o serviço de saúde, no qual trabalhavam no momento, variava em média de três a nove anos, considerando o conjunto dos alunos.

Até 1985, quando o curso se restringia aos profissionais da área biológica, predominavam médicos e enfermeiros. A partir de 1986, com a abertura do curso a outros profissionais, passou a haver maior variedade no campo profissional. Observa-se também que, apesar de os profissionais de medicina constituírem cerca de $40 \%$ da massa de trabalhadores estimada para o setor saúde no Brasil, em 1996 (Girardi, 1996:25), constatou-se uma diminuição do número de médicos matriculados no curso e, em contrapartida, um aumento do número de enfermeiros, conforme a Figura 2.

Acompanhando a complexidade da constituição das equipes de saúde, faziam parte das turmas dos cursos de 1993 e 1995 além de médicos, enfermeiros, odontólogos e psicólogos, profissionais de outras disciplinas da área da Saúde, bem como das Ciências Exatas, Humanas e técnicas, como Engenharia e Educação Física. Em sua grande maioria, esses profissionais pertenciam aos níveis locais e centrais dos serviços de saúde públicos de Campinas e municípios vizinhos. Mas havia também alguns alunos procedentes da capital, São Paulo, e de outros estados, sobretudo Minas Gerais.

Esses profissionais exerciam funções de atendimento e assistência, de gerência e administração, de ensino e treinamento, de pesquisa e supervisão, em ordem decrescente, considerando o número de profissionais em cada uma, sendo comum a realização concomitante de dois ou mais tipos de atividade. No quarto momento da investigação, respectivamente oito e seis meses após a conclusão do curso, constatou-se não ter havido muitas mudanças nas funções desenvolvidas pelos alunos, embora eles referissem ter observado um aumento de atividades e de responsabilidades.

Nas duas turmas, o número de alunos que fizeram seus cursos de graduação em universidades privadas era maior do que o dos forma- 
Caracterização de clientela do Curso de Especialização em Saúde Pública do DMPS/FCM/UNICAMP, segundo sexo e setor de atividade, 1985 a 1995.

\begin{tabular}{lcccccccc}
\hline & 1985 & 1986 & 1987 & 1988 & 1989 & 1991 & 1993 & 1995 \\
\hline $\begin{array}{l}\text { Sexo } \\
\text { Masculino }\end{array}$ & 13 & 11 & 12 & 12 & 07 & 10 & 16 & 07 \\
$\quad$ Feminino & 27 & 28 & 30 & 27 & 35 & 25 & 31 & 28 \\
Setor de atividade & & & & & & & & \\
$\quad$ Público & 37 & 38 & 35 & 22 & 25 & 30 & 32 & 28 \\
$\quad$ Privado & - & - & - & 01 & 02 & - & - & 01 \\
$\quad$ Universidades & 03 & 01 & 07 & 16 & 15 & 05 & 05 & 06 \\
\hline
\end{tabular}

Fonte: Arquivo do DMPS.

Em 1990, 1992 e 1994 o curso não foi ministrado.

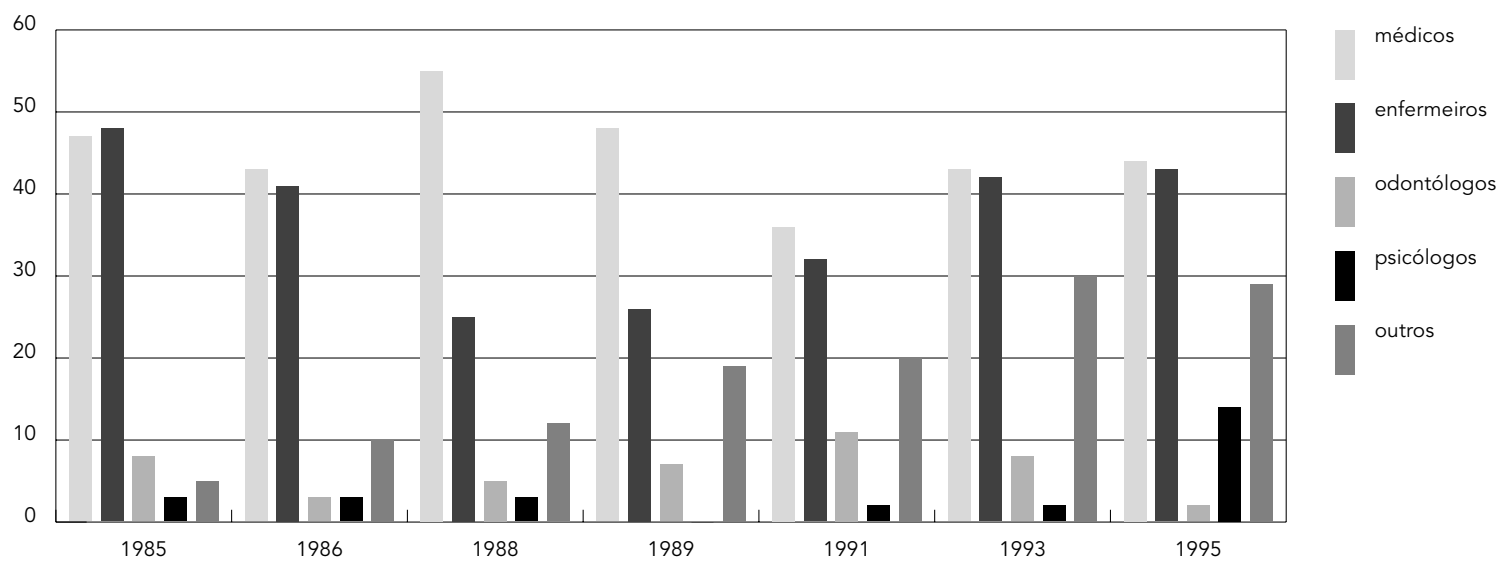

Fonte: Arquivo do DMSP.

* Excluindo-se 1987 (sem informação), 1990, 1992 e 1994 (não houve o curso).

dos em universidades públicas, respectivamente, $60 \%$ e $40 \%$. Dentre as instituições privadas, predominava a PUC de Campinas, seguida pela PUC de São Paulo.

Dentre as dificuldades enfrentadas no cotidiano dos serviços, e que interferiam negativamente no trabalho de cada um, os entrevistados das duas turmas foram unânimes em referir os seguintes aspectos, relacionados em ordem decrescente de acordo com o número de citações: problemas relacionados a recursos humanos, tais como número reduzido de profissionais, baixos salários, falta de valorização profissional, carreirismo e competição, falta de compromisso e de envolvimento dos trabalhadores com a população e a inexistência de uma política estadual e municipal em relação aos recursos humanos; problemas relativos ao direcionamento da política de saúde (nível macro) e à forma de exercício de poder no interior dos serviços (nível micro). Neste grupo, citavam-se desde o descaso institucional dos ní- 
veis centrais, não se capacitando para exercer suas funções na implantação efetiva do SUS, até a contradição entre um discurso democrático e uma prática autoritária, centralizadora e burocratizada. Mencionou-se também a ocorrência de conflitos entre o Conselho Local e o Centro de Saúde. Foram referidos problemas efetivos de infra-estrutura inadequada e ineficiente, quanto a transporte, medicamentos, equipamentos, exames e espaço físico; em último, problemas relativos à inexistência de planejamento e/ou planejamento ineficaz, gerado pela falta de cooperação e de troca entre as equipes, às reuniões improdutivas, à baixa resolutividade e ao excesso de demanda. Para alguns profissionais/alunos tais dificuldades causavam angústia, frustração e estresse.

No entanto, houve referência também aos aspectos agradáveis que estimulavam o trabalho em saúde pública, dentre os quais, por ordem de prioridade, foram mencionados: em primeiro lugar, a satisfação pelos resultados obtidos em várias situações, o reconhecimento do trabalho por parte da população e da instituição, a constatação de haver possibilidades concretas de atuar para transformar a realidade social e as condições de saúde da população, de melhorar o sistema público de saúde e, por fim, de acreditar na possibilidade de realizar projetos inovadores; em segundo lugar, o trabalho em equipe (compromisso, dedicação, companheirismo, solidariedade e troca entre grupos de profissionais) e a possibilidade de participar de equipes multidisciplinares; em terceiro lugar, o aperfeiçoamento pessoal, o poder evoluir como sujeito (político e profissional).

Provavelmente, por tudo isso, ao serem questionados se gostariam de mudar a ocupação atual para outra fora do campo da saúde pública, cerca de $80 \%$ dos alunos de ambas as turmas responderam que não. Dos poucos que manifestaram vontade de mudar, a referência é de alguma mudança dentro do próprio serviço.

Ao longo desses anos, tem sido definido como principal objetivo dos Cursos de Especialização em Saúde Pública possibilitar aos alunos o desenvolvimento de três níveis de competência: político-crítica, técnico-instrumental e ética. Trata-se, na verdade, da competência indispensável ao desenvolvimento de qualquer trabalho em saúde, da consciência do papel profissional de cada um, conforme L'Abbate (1994, 1997c). Pois bem, no primeiro momento da avaliação e por meio de respostas a questionário específico, os alunos manifestaram a necessidade de aperfeiçoamento nas três dimensões, enfatizando a político-crítica, e perceberam a necessidade de integração destas, bem como o fato de que são buscadas durante toda a trajetória profissional.

Coerente com essa visão ampla de capacitação, os alunos manifestaram suas expectativas em relação ao curso, as quais, resumidamente, podem ser agrupadas também por ordem de número de respostas: em primeiro lugar, subsidiar a prática, relacionar teoria e prática; em segundo, ampliar conhecimentos gerais no campo da saúde pública; em terceiro, aperfeiçoar a capacitação, tendo alguns mencionado ainda a possibilidade de carreira no serviço; em quarto, desenvolver uma visão crítica, relacionando as questões do campo da saúde pública com a problemática da sociedade mais ampla; em quinto, capacitar-se em torno de questões específicas de gerenciamento e, por último, trocar experiências com os colegas de classe.

As expectativas diziam respeito também aos conteúdos das várias disciplinas do curso, e, nos outros questionários aplicados posteriormente, perguntava-se ao aluno se aquelas estavam sendo satisfeitas. Muitas vezes, a resposta era afirmativa, e muitas vezes, também, havia a constatação de que, apesar de o curso representar um momento privilegiado de capacitação, a procura de aperfeiçoamento, manifestada nas expectativas, era um desejo a ser buscado sempre, ultrapassando de muito o espaço-tempo do curso.

\section{Segundo e terceiro momentos: a análise das disciplinas obrigatórias e optativas}

A divisão das disciplinas em dois módulos correspondia a uma divisão, não muita rígida, entre conteúdos teóricos e aplicados, conforme ementas relacionadas em UNICAMP (19841993). Considere-se que, mesmo dentre as disciplinas obrigatórias, Pesquisa em Serviços de Saúde e Práticas de Saúde Pública possuem um caráter mais prático ou aplicado.

Mas no início do curso, tendo em vista uma certa heterogeneidade dos alunos, sua não familiaridade com as Ciências Sociais, a Epidemiologia, a Bioestatística e as Teorias do Planejamento, havia dificuldades quanto à assimilação dos conteúdos, ao entendimento dos textos e à necessidade de mais disciplina e tempo para leitura. Havia até mesmo uma certa perplexidade, como se dissessem: "Será que preciso saber tudo isto para ser sanitarista?".

É o que aparece nos questionários respondidos pelos alunos da turma de 1993, mesclado de comentários reconhecendo a relevância des- 
sas disciplinas, pois, por meio delas, de acordo com as respostas de alguns alunos, "adquiri maior embasamento para o exercício da função de sanitarista" e "maior motivação para o exercício profissional"; "pude observar a importância dos conhecimentos das Ciências Sociais"; "obtive subsídios para a compreensão histórica e funcional do SUS”. Outros alunos referiram ainda ter passado por "um processo de amadurecimento" ou adquirido "uma nova visão de mundo e uma mudança de valores". Quase todos relataram a necessidade de aprofundar determinados conteúdos ou até de acrescentar outros (L'Abbate et al., 1997a:39).

Essas necessidades traziam, como conseqüência, a demanda por aumento de carga horária, reivindicação constantemente explicitada e difícil de ser atendida: o curso teria uma carga horária incompatível com o compromisso com as instituições de origem dos alunos, no sentido de eles se afastarem, no máximo, dois dias e meio por semana.

Se os conteúdos eram considerados relevantes, os processos didáticos utilizados na sua transmissão foram, muitas vezes, criticados. E a sugestão era sempre a de que os docentes deveriam trabalhar melhor a relação teoria-prática. Dentre as estratégias didáticas sugeridas como facilitadoras da aprendizagem, eram freqüentemente indicados: maior utilização de exercícios e trabalhos em pequenos grupos e melhor adequação na utilização do psicodrama. Disciplinas que exigiam, pelos seus conteúdos, a participação de um número muito grande de docentes eram criticadas, justamente por faltar articulação entre aulas e palestras.

Mas essa análise quanto à relação entre os conteúdos dos dois blocos, se observada como um todo, é altamente positiva, para se pensar tanto a construção do curso, como a formação do sanitarista. Se o que se busca é a competência nos três níveis, conforme comentado, é indispensável a relação entre teoria e prática. Por mais que os profissionais/alunos não estivessem totalmente satisfeitos com o curso quanto à busca dessa relação (nem sei se seria possível, porque ela é inesgotável), ao perceberem, ao final do curso, até que ponto conteúdos trabalhados no início (quando, inclusive, pareciam muito teóricos e distantes) relacionavamse com conteúdos e habilidades específicas, os sujeitos conseguiram articular teoria e prática. Isso tem a ver com a importância da proposta didático-pedagógica e mais ainda com a convicção de que é necessário "pensar para agire agir para pensar melhor” (Cabral, apud Paim, 1993:7).
Discutindo sobre a aplicabilidade dos conteúdos e habilidades das disciplinas optativas, a totalidade dos alunos das duas turmas acreditava na possibilidade de aplicá-los, seja de forma imediata, seja a médio e longo prazo. Mais ainda, citavam planos e projetos que já estavam realizando, incorporando o aprendido. A discussão em torno desse leque de possibilidades foi feita, sobretudo, durante a realização do grupo focal, como se verá adiante.

Finalmente, retomando as expectativas manifestadas no início do curso, grande parte delas foi contemplada segundo os alunos. No curso de 1993, a disciplina que melhor atendeu às expectativas foi Educação em Saúde; no de 1995, foi a de Saúde Ambiental/Vigilância Sanitária (L'Abbate et al., 1997a, 1997b).

\section{Quarto momento: a análise alguns meses depois de concluído o curso}

Se, ao concluir o curso, os profissionais indicavam possibilidades de aplicar conhecimentos e habilidades no cotidiano do seu trabalho, ao se reunirem, alguns meses depois, mediante carta-convite da coordenadora da pesquisa, o que teriam a dizer sobre isso? O registro das reflexões sobre essa temática foi feito, conforme indicado na Metodologia, em um questionário individual, enviado pelo correio e por uma entrevista em grupo - o grupo focal. Responderam ao questionário 22 egressos da turma de 1993, e 14 da de 1995; participaram do grupo focal 19 ex-alunos da turma de 1993 e apenas seis daquela de 1995.

De acordo com as informações trazidas pelos questionários, de forma unânime, os profissionais afirmaram ter ocorrido um aperfeiçoamento no seu trabalho, quando se consideram as três dimensões da competência: técnica-instrumental, político-crítica e ética, de forma coerente ao dito ao final do curso. Contudo, são aspectos em constante desenvolvimento, conforme a fala de um dos ex-alunos: “(...) me sinto melhor com relação às competências após o curso, sendo que elas vão sendo aprimoradas com o tempo, com o trabalho desenvolvido" (L'Abbate et al., 1997b:136).

Tal aperfeiçoamento da competência pode não ter trazido mudanças de trabalho muito significativas do ponto de vista formal, levando, por exemplo, a assumir postos de comando. Entretanto, houve menção, nos dois grupos, ao acréscimo de atividades e sobretudo ao aumento de responsabilidades, principalmente relacionadas às áreas de planejamento e programação. Alguns atribuíam tais situações 
à melhor compreensão do seu papel profissional na instituição, outros às próprias necessidades das instituições. Raras vezes tal ampliação era acompanhada de algum tipo de acesso a postos formais de chefia e muito menos ao aumento de salário. Ou seja, a maioria dos egressos experimentava concretamente a ausência de definição de uma política de recursos humanos.

Mesmo afirmando ter adquirido maior compreensão do funcionamento da instituição onde atuavam, em razão do aprendido no curso, nenhum dos ex-alunos da turma de 1993 se sentiu apoiado integralmente pelo serviço para implementar projetos após o término do curso. Cerca de $80 \%$ afirmaram ter apoio apenas "em termos”. As explicações para o fato iam desde a existência de disputas de poder e resistência a mudanças, até a incompatibilidade de projetos políticos.

Aos ex-alunos da turma de 1995 solicitouse que analisassem a cultura institucional na qual estavam inseridos, procurando avaliar sua própria participação dentro dela. A fala de um dos entrevistados foi muito interessante e pode ser considerada quase como uma síntese: "Embora haja a cultura de que não tem mais jeito, que tudo parece ligado ao desânimo, egoísmo e improvisação, levando ao desrespeito ao paciente, sinto-me privilegiado no meu local de trabalho, com uma equipe muito interessante, sensível e capacitada na sua maioria, onde se tenta vencer bravamente esses atropelos, o que me incentiva a continuar" (L'Abbate et al., 1997b:130).

Diante de tantos desafios, como se aperfeiçoar ainda mais? Como continuar a formação? Os dois grupos de alunos reafirmaram a importância do suporte da Universidade, no caso o Departamento de Medicina Preventiva e Social, mediante um determinado grupo de professores e profissionais dos laboratórios, não só para outros cursos, como também para assessoria e supervisão dos projetos que esses profissionais, em grande parte, estimulados pelo próprio curso, passaram a desenvolver. Trata-se praticamente de um Programa de Educação Continuada ou de Educação Permanente, propostas sugeridas por autores como Paim (1993) e Paim \& Nunes (1992).

Por último, todos os sujeitos pesquisados recomendariam o curso para os colegas que quisessem se especializar em saúde pública. Sem dúvida, uma avaliação altamente positiva do curso. Em resumo, como disse um exaluno da turma de 1995: "Levo lembranças boas do curso: foi um ganho adequado em alguns aspectos, inadequado em outros, mas nitidamente positivo em termos de contribuição para o desenvolvimento da Saúde Pública" (L'Abbate et al., 1997b:137).

Os encontros, ou melhor, os reencontros, dos ex-alunos para discutir o curso, mediante a técnica do grupo focal, respectivamente em agosto de 1993 e em dezembro de 1996, tiveram o papel de sintetizar as colocações feitas nos vários questionários individuais, aprofundando as temáticas abordadas, mencionando outras ainda não tratadas, na forma peculiar a tal técnica (Vieira et al., 1995). Tudo isso foi trabalhado valendo-se da inter-subjetividade dos sujeitos, que não apenas expõem o que pensam e o que sentem, mas dialogam a respeito, com os outros participantes da mesma experiência. Nas duas ocasiões, os egressos debateram a respeito de um amplo conjunto de temas, parte dos quais são resumidos a seguir.

\section{Motivações para fazer o curso e por que na UNICAMP}

Para muitos, a motivação existia desde a graduação, para outros o interesse veio com a inserção no serviço. Quanto a fazer o curso na UNICAMP, além de facilidades como proximidade e acessibilidade, era importante já ter referência do curso e do corpo docente. Havia também uma certa idealização, presente, por exemplo, nesta fala de um ex-aluno: “O curso é a possibilidade da gente sonhar junto uma proposta de trabalho prá saúde, melhor, que é o que a gente deseja!" (L'Abbate et al., 1997a:73).

\section{Praticar o aprendido}

Houve inúmeras referências à utilização das técnicas e dinâmicas aprendidas na disciplina de Educação em Saúde, à utilização do modelo do PES (Planejamento Estratégico Situacional), aprendido em Planejamento, ao processo de investigação da disciplina de Pesquisa, assim por diante. No debate sobre as diferenças entre a maneira de vivenciar esses e outros instrumentais no curso e a forma de aplicá-los no serviço, na comparação que se fazia, aparecia, de um lado, um grande nível de satisfação do tipo: "Olha! Estou conseguindo aplicar muito do que aprendi (...) você, com o instrumental que você recebeu, consegue aos pouquinhos implementar seu trabalho", e uma certa idealização: "Se não se aplica um determinado instrumento exatamente da mesma forma que na sala de aula, pode parecer que não se está aplicando o aprendido". Na realidade, a conclusão é a de 
que instrumentos e técnicas são recursos que muitas vezes devem ser adaptados para serem utilizados nos serviços e que não devem ser valorizados em e por si mesmos, mas pelo seu poder de mediação de situações e conceitos que se queiram analisar (L’Abbate, 1994, 1997c).

\section{Uma relação complicada: alunos $\mathrm{x}$ instituição}

A relação dos egressos com a sua instituição de origem foi motivo de muita discussão durante a realização do grupo focal. A instituição, considerada às vezes como o próprio serviço e às vezes como o nível central da Secretaria Municipal de Saúde de Campinas, de onde provinha a grande maioria dos alunos, atuava todo o tempo, colocando limites e possibilidades às atividades e projetos dos alunos recém-saídos do curso.

As situações comentadas relacionavam-se a três momentos: antes do curso, como havia sido o processo de liberação para o profissional ausentar-se dois dias e meio por semana para freqüentar o curso; durante o curso, como dar conta da demanda nas unidades, como "repor as horas, como compensar a ausência"; e depois do curso, como aproveitar melhor o "novo' sanitarista.

Em relação ao momento anterior, após a aprovação no processo de seleção, houve relatos de casos nos quais a direção da instituição colocou empecilhos para o profissional freqüentar o curso. Em relação à turma de 1993, essas situações foram mais comuns, tendo em vista a coincidência do início do curso com o início da nova administração municipal. Registre-se que, após o processo de seleção, cerca de cinco profissionais aprovados não foram liberados pela Secretaria Municipal de Saúde, por estarem em cargos de direção, sendo considerada indispensável sua presença em tempo integral na instituição naquele momento. Mas entre os egressos da turma de 1995 também houve referência a situações em que o profissional "precisou lutar muito para ser liberado" (L'Abbate et al., 1997b:149).

Alguns profissionais foram liberados mediante compromisso de repor as horas do curso, sobretudo quando se tratava de trabalhadores ligados à assistência, conforme depoimento de uma aluna da turma de 1995: "Eles não me liberaram para fazer o curso, então eu paguei [ou seja repôs semanalmente as horas utilizadas pelo curso] todos os horários, isso também acho que prejudicou no próprio aproveitamento" (L'Abbate et al., 1997b:153).
Outros não repunham horas de trabalho, mas sofriam muita cobrança por parte dos colegas, que se sentiam sobrecarregados. Cobrança e também críticas, às vezes bem desagradáveis, conforme o depoimento de uma exaluna da turma de 1993, que, ao longo do curso, ouvia comentários dos colegas em torno das diferenças entre " a elite trabalhante e a elite pensante": a primeira permanecendo no serviço "segurando a barra", enquanto a outra fazia cursos fora, aperfeiçoando-se. "Então isso incomoda, e você tem de conviver com isto durante todo o curso" (L'Abbate et al., 1997a:81).

Finalmente, os egressos debateram o que ocorreu ao término do curso, com a sua volta ao serviço em tempo integral. Também, nesse caso, os relatos apontaram quatro situações experimentadas pelos ex-alunos: a) indiferença dos colegas e da chefia e poucas mudanças em relação às funções e atribuições do egresso; b) a sobrecarga de trabalho: "Bom, você voltou, agora toda a vigilância é sua, toda campanha é sua! Você é sanitarista, agora nós vamos cruzar os braços" (L'Abbate et al., 1997a:81); c) a desvalorização, porque voltou sanitarista, mas continuou fazendo exatamente o que fazia antes; d) o respeito, representado algumas vezes pela ascensão e mudança de cargo, nem sempre acompanhadas, porém, da respectiva valorização financeira.

\section{Implantação de novos projetos: sucessos e fracassos}

Os egressos 'retornaram' ao trabalho com diversas idéias e propostas, algumas de sua própria iniciativa, outras em virtude da participação em planos já em andamento, tais como: formar grupos específicos com a clientela e a comunidade, implementar o aperfeiçoamento da capacitação das equipes de trabalho, efetivar projetos na área de nutrição e de saneamento etc. Houve muitas queixas sobre a falta de apoio da chefia e dos colegas para suas iniciativas, e o sucesso foi obtido, sobretudo, por aqueles que conseguiram negociar os 'novos' projetos com a equipe de trabalho, conseguindo apoio e colaboração.

Além da vontade de inovar e de criar, havia também a necessidade de fugir da rotina, sobretudo a rotina de atender à demanda, necessidade manifestada em vários momentos do debate. Reiteradamente, retornava-se às expectativas de que, voltando ao serviço com o título de especialista em saúde pública ou sanitarista, o egresso passaria a fazer outro tipo de trabalho. Para a grande maioria isso não 
ocorreu: "A gente é cobrada mesmo é para esse papel de 'peão', mesmo pela população, o que ela está habituada (...) é esse papel”, dizia um dos participantes da reunião. Outra participante, médica pediatra, interrogava-se: “...então fico pensando quando vou poder ser sanitarista (...). Quando eu voltei, voltou foi a pediatra. Sanitarista, o que é isto? É a demanda, demanda, atendimento, atendimento (...). Eu sou pediatra, tocadora de serviço" (L'Abbate et al., 1997a: 82, 96, 97).

Para uma das ex-alunas, diante da frustração por não ter conseguido implantar nenhum projeto proposto, quando do término do curso, a saída foi pedir demissão do serviço, fato ocorrido poucos dias antes da reunião da turma de 1993. A descrição do fato trouxe muita emoção e até lágrimas, não apenas para a personagem, como também para os colegas. A profissional afirmava: "Eu pedi demissão do serviço [Secretaria Municipal de Saúde], mas não desisti da Saúde Pública. Saí, porque nenhuma das minhas propostas foi aceita pela direção do Centro de Saúde onde eu trabalhava, e eu não tinha mais o que fazer lá" (L'Abbate et al., 1997a:91). Embora não se tenham todos os elementos para julgar a situação e a própria condição dessa profissional para deixar o emprego, há que se lamentar que uma instituição libere um dos seus profissionais cinco períodos por semana, durante um ano, para fazer um curso, e que, ao voltar, esse profissional não tenha condições de implementar o que aprendeu.

\section{Necessidade de continuar a capacitação}

Reafirmando aquilo que haviam comentado no questionário individual, os egressos, em sua totalidade, manifestaram a vontade de continuar a formação, seja através de outros cursos, seja mediante atividades relacionadas ao acompanhamento e supervisão dos projetos que estavam implementando nos serviços. O debate se deu em torno da melhor forma de organizar cursos, disciplinas, assessorias e/ou supervisão.

\section{Solidariedade entre os colegas durante o curso}

O relacionamento entre os alunos durante o curso propiciou um clima de amizade e cumplicidade, criando forte identidade grupal, permitindo não apenas compartilhar novas idéias e sonhos, como também 'agüentar' as dificuldades do cotidiano dos serviços. Em ra- zão do significado afetivo dessa convivência e das múltiplas situações de troca ocorridas durante o ano do curso, o encontro dos egressos, aqui analisado, revestiu-se de um significado que ultrapassou, de muito, os objetivos de avaliar o curso e os problemas da 'volta' ao trabalho. Significou também reforçar a crença na força trazida por um grupo, cujos componentes acreditam em e comungam idéias e valores semelhantes, crendo, sobretudo, na possibilidade de lutar por estes.

\section{Conclusões}

Dentre as principais conclusões, considerando a análise dos quatro momentos da investigação, é importante destacar o compromisso dos profissionais/alunos com o trabalho na saúde pública. Ainda que essa afirmação possa parecer redundante - afinal trata-se de um grupo de pessoas que escolheu fazer uma especialização na área -, é animador constatar tal nível de envolvimento, mesmo porque ele está pautado numa análise crítica dos problemas que dificultam e, às vezes, impedem as mudanças. Constatou-se também a relevância do curso para a capacitação profissional dos alunos, com a perspectiva de constante adequação dos conteúdos e aperfeiçoamento do processo didático-pedagógico. Nesse sentido, é necessário que coordenadores e professores do curso façam um esforço a fim de aprimorar o processo ensino-aprendizagem, combinando a transmissão de grande quantidade e variedade de informações, assim como docentes com estratégias que garantam o respeito às relações entre o cognitivo e o afetivo, presentes em todo processo de ensino, mesmo entre adultos, conforme assinalam Weinstein \& Fantini (1973). Além disso, em todas as situações possíveis, devem-se buscar maneiras cada vez mais eficientes de relacionar teoria e prática, aproveitando ao máximo as experiências dos profissionais/alunos.

Há necessidade urgente de uma revisão da política de capacitação de recursos humanos que atente para os momentos antes, durante e após o curso, ou seja: o processo de liberação, o funcionamento do serviço durante a ausência do profissional, o aproveitamento posterior do egresso e o estabelecimento de carreiras condizentes com os vários níveis. Isso só seria possível mediante um amplo processo de envolvimento das instituições às quais pertencem os alunos e o departamento/universidade que ministra o curso, visando promover maior integração entre conteúdos, processos didáti- 
cos, pesquisas e, principalmente, projetos de intervenção.

Finalmente, é necessário implantar um sistema de educação continuada ou até de educação permanente, bem como de processos contínuos de acompanhamento e supervisão.

Em virtude da pequena ou quase nenhuma oferta de cursos de Especialização em Saúde Pública por parte de instituições públicas no Estado de São Paulo, o curso oferecido pelo

\section{Referências}

BERTRAND, J. T.; BROWN, J. \& WARD, V. M., 1992. Techniques for analyzing focus group data. Evaluation Review, 16:198-209.

CAMPOS, G. W. S., 1994. Considerações sobre a arte e a ciência da mudança: Revolução e reforma das pessoas. O caso da saúde. In: Inventando a Mudança na Saúde (L. O. Cecílio, org.), pp. 29-87, São Paulo: Editora Hucitec.

GARRAFA, V., 1995. Novos paradigmas para a saúde A ética da responsabilidade: Individual e pública. Saúde em Debate, 48:47-50.

GIRARDI, S. N., 1996. Flexibilização dos mercados de trabalho e escolha moral. Divulgação em Saúde para Debate, 14:23-32.

GONÇALVES, R. B. M., 1994. Tecnologia e Organização Social das Práticas de Saúde: Características Tecnológicas do Processo de Trabalho na Rede Estadual dos Centros de Saúde de São Paulo. São Paulo: Editora Hucitec/Rio de Janeiro: Abrasco.

GONÇALVES, R. B. M., 1992. Práticas de Saúde: Processos de trabalho e necessidades. Cadernos CEFOR, Textos. São Paulo: CEFOR.

GOODE, W. J. \& HATT, P. K., 1972. Como construir um questionário. In: Métodos em Pesquisa Social, 4a Ed., pp. 171-218, São Paulo: Companhia Editora Nacional.

L'ABBATE, S., 1994. Educação em Saúde: Uma nova abordagem. Cadernos de Saúde Pública, 10:481490.

L'ABBATE, S., 1995. Agentes de trabalho/sujeitos? Repensando a capacitação de Recursos Humanos em Saúde Coletiva. In: Dilemas e Desafios das Ciências Sociais na Saúde Coletiva (A. M. Canesqui, org.), pp. 151-161. São Paulo: Editora Hucitec/ Rio de Janeiro: Abrasco.

L'ABBATE, S.; PINHEIRO, M. A. B.; SANTOS, L. M. M. P.; VIEIRA, C. M.; BARROS, N. F. \& STENZEL, A. C. B., 1997a. Acompanhamento e Avaliação do Curso de Especialização em Saúde Pública do Departamento de Medicina Preventiva e Social da Faculdade de Ciências Médicas da UNICAMP: Turmas de 1991 e 1993. Relatório Técnico. Campinas: CNPq.

L'ABBATE, S.; ANDRÉ, D.; OLIVEIRA, M. A. \& MENDES, M. I., 1997b. Acompanhamento e Avaliação do Curso de Especialização em Saúde Pública do Departamento de Medicina Preventiva e Social da Faculdade de Ciências Médicas da UNICAMP. Turma de 1995/96. Relatório Técnico. Campinas: CNPq.
Departamento de Medicina Preventiva e Social da Faculdade de Ciências Médicas da UNICAMP tornou-se uma das únicas opções para os profissionais de saúde. Daí a relevância de sua continuidade. Prevê-se, com a experiência anterior, o contínuo aperfeiçoamento do curso, sobretudo quanto à maior integração dos conteúdos, libertando-se de algumas divisões de caráter disciplinar, bem como a maior utilização de métodos didáticos inovadores.
L'ABBATE, S., 1997c. Comunicação e educação: Uma prática de saúde. In: Agir em Saúde: Um Desafio para o Público (E. E. Merhy \& R. Onocko, org.), pp. 267-292, São Paulo: Editora Hucitec/Buenos Aires: Lugar Editorial.

MACHADO, M. H., 1995. Trabalhadores da saúde: Um bem público. Saúde em Debate, 48:54-57.

MATTOS, M. L., 1996. Recursos Humanos e o Novo Trabalhador em Saúde: A Experiência da Secretaria Municipal de Saúde na Cidade de São Paulo durante a Gestão do Partido dos Trabalhadores (1989-1992). Dissertação de Mestrado, Campinas: Faculdade de Ciências Médicas, UNICAMP.

MS/FNS/CENEPI (Ministério da Saúde/Fundação Nacional da Saúde/CENEPI), 1993. Documento de Avaliação para o Programa de Capacitação em Epidemiologia. Brasília: MS.

PAIM, J. S., 1993. Marco de referência para um programa de educação continuada em Saúde Coletiva. Revista Brasileira de Educação Médica, 17:7-13.

PAIM, J. S. \& NUNES, T. C. M., 1992. Contribuições para um programa de Educação Continuada em Saúde Coletiva. Cadernos de Saúde Pública, 8: 262-269.

RICHARDSON, R. J.; PERES, J. A. S.; CORREIA, L. M. \& WANDERLEY, J. C. V., 1985. Pesquisa Social: Métodos e Técnicas. São Paulo: Atlas.

RIOS, T. A., 1993. Ética e Competência. São Paulo: Cortez.

SCHRAIBER, L. B., 1991. A Qualidade dos Serviços e a Capacitação Profissional. Texto do Curso de Aprimoramento Integrado em Recursos Humanos, Saúde Mental e Saúde do Trabalhador. Convênio CEFOR/SMSSP/FMUSP. São Paulo. (mimeo.)

UNICAMP (Universidade Estadual de Campinas), 1984-1993. Processo 1657/84 (Vol. 4). Campinas: Diretoria Acadêmica/UNICAMP.

WEINSTEIN, G. \& FANTINI, M. D., 1973. La Enseñanza por el Afecto: Vida Emocional y Aprendizaje. Buenos Aires: Paidós.

WESTPHAL, M., 1992. Participação Popular e Políticas Municipais de Saúde. Tese de Livre Docência, São Paulo: Faculdade de Saúde Pública/USP.

WESTPHAL, M. F.; BÓGUS, C. M. \& FARIA, M. M., 1996. Grupos focais: Experiências precursoras em programas educativos em saúde no Brasil. Boletín de la Oficina Sanitaria Panamericana, 120: 472-482. 